\title{
Female mate choice in convict cichlids is transitive and consistent with a self-referent directional preference
}

\author{
François-Xavier Dechaume-Moncharmont ${ }^{1 *}$, Marine Freychet ${ }^{1}$, Sébastien Motreuil ${ }^{1}$ and Frank Cézilly ${ }^{1,2}$
}

\begin{abstract}
Introduction: One of the most important decisions that an animal has to make in its life is choosing a mate. Although most studies in sexual selection assume that mate choice is rational, this assumption has not been tested seriously. A crucial component of rationality is that animals exhibit transitive choices: if an individual prefers option A over $B$, and B over $C$, then it also prefers $A$ over $C$.

Results: We assessed transitivity in mate choice: 40 female convict cichlids had to make a series of binary choices between males of varying size. Ninety percent of females showed transitive choices. The mean preference index was significantly higher when a female chose between their most preferred and least preferred male (male $1 \mathrm{vs}$. male 3) compared to when they chose between males of adjacent ranks ( 1 vs. 2 or 2 vs. 3). The results are consistent with a simple underlying preference function leading to transitive choice: females preferred males about one third larger than themselves. This rule of thumb correctly predicted which male was preferred in $67 \%$ of the cases and the ordering in binary choices in $78 \%$ of cases.

Conclusions: This study provides the first evidence for strong stochastic transitivity in a context of mate choice. The females exhibited ordinal preferences and the direction and magnitude of these preferences could be predicted from a simple rule. The females do not necessarily compare two males to choose the best; it is sufficient to use a self-referent evaluation. Such a simple decision rule has important implications for the evolution of the mating strategies and it is consistent with patterns of assortative mating repeatedly observed at population level.
\end{abstract}

Keywords: Mate choice, Rationality, Transitivity, Assortative mating, Self-referent directional preference, Amatitlania nigrofasciata

\section{Introduction}

A crucial question about adaptive mate choice is to what extent individuals show some level of rationality when choosing a mate [1-4]. Assuming that natural selection has shaped the preference functions of animals, mate choice is expected to maximize fitness [5-7]. Ideally, then, animals should be able to assign to each potential mate a value on a single dimension directly related to fitness, and their probability of choosing one potential mate over another should be a monotonic function of their respective values.

\footnotetext{
* Correspondence: fx.dechaume@u-bourgogne.fr

'Équipe écologie évolutive, UMR CNRS 6282 Biogéosciences, Université de Bourgogne, 6 boulevard Gabriel, 21000 Dijon, France

Full list of author information is available at the end of the article
}

Rationality in choice is traditionally equated in behavioural ecology with consistency across time, transitivity and independence from irrelevant alternatives $[1,8]$. Although the repeatability of mating preferences [9] and, to a lesser extent, independence from irrelevant alternatives $[10,11]$ has been investigated in several species, analyses of transitivity remain scarce in the context of mate choice. The only previous experimental study assessed transitivity in female preference for male calls in the Tungara frog, Physalaemus pustulosus [12-14]. This study was inconclusive, however, as there was no sufficient evidence for either transitivity or intransitivity in mate choice. Yet, transitivity is arguably the most fundamental axiom of rational choice $[15,16]$, and has been previously investigated in animal species in various other

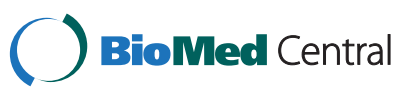


contexts, such as foraging decisions [17-20], nest choice $[21,22]$ or dominance relationships [23,24].

Transitivity in choice, in its simplest definition [25], states that if an individual prefers option A over B and B over $\mathrm{C}$, then it also prefers $\mathrm{A}$ over $\mathrm{C}$. However, the level of expression of transitivity depends on whether options can be ranked on an ordinal or an interval scale [26]. Consider three alternative mating options $\mathrm{A}, \mathrm{B}$, and $\mathrm{C}$. Let $\mathrm{P}(\mathrm{A}, \mathrm{B})$ be the probability of choosing option $\mathrm{A}$ from the choice set $\{A, B\}$. Choice proportions conform to weak stochastic transitivity (WST) if when $\mathrm{P}(\mathrm{A}, \mathrm{B}) \geq 0.5$ and $\mathrm{P}(\mathrm{B}, \mathrm{C}) \geq 0.5$, then $\mathrm{P}(\mathrm{A}, \mathrm{C}) \geq 0.5$. Evidence for WST validates only the assumption of one-dimensional choice, meaning that the options can be ordered, but not quantified, on a common scale. By contrast, strong stochastic transitivity (SST) occurs if $\mathrm{P}(\mathrm{A}, \mathrm{C}) \geq \max \{\mathrm{P}(\mathrm{A}, \mathrm{B}), \mathrm{P}(\mathrm{B}, \mathrm{C})\}$ $[19,27-29]$, and would be indicative that not only ordinal preference holds, but that a value on a common quantitative scale can be assigned to each mating option [26].

Here, we assess transitivity in choice in relation to mating patterns in female convict cichlids, Amatitlania nigrofasciata, which is a model species in mate choice [30-33]. In this monogamous and territorial fish species with bi-parental care, females generally benefit from mating with a large male, in terms of breeding success [34] and protection of offspring against predators or competitors [35]. However, large males in this species are particularly aggressive, and females must weigh the benefits of pairing with a large male against negative fitness effects linked to asymmetric aggressive interactions [36] and increased risk of filial cannibalism $[37,38]$.

Preference for partner size is thus expected to be finely tuned in this species. Previous studies have established that males show a preference for gravid, large females [39], whereas the preference of females in relation to male size remains controversial. Depending on the study, females either preferred larger males [30,40-42], or males of similar size to themselves [43]. Typically, female preference was assessed by simultaneously confronting a focal female with two [30,42] or three males [44] differing in size. Preference is then inferred from the relative amount of time spent next to each male. A female is thus assumed to prefer male A over male B $(\mathrm{A}>\mathrm{B})$ when the amount of time spent in front of male A divided by the total amount of time spent in the two choice areas, considered hereafter as the preference index, is above $50 \%$. This measure has been shown to correlate with female reproductive preference in convict cichlids [42] and other cichlid fish [45]. No study, however, has examined transitivity in female choice when confronted with several males.

Most theory predicts that violation of rationality will only occur when the available options differ in multiple dimensions ([46,47] but see [48]). All previous experimental studies of female choice in convict cichlids consisted in confronted females with live males of different sizes and recorded their behaviour and time spent in front of each male (review in [42]). However, in addition to size, males may vary in respect to several other phenotypic attributes, such that female choice might not necessarily be one-dimensional. One way to confirm that females indeed prioritize one dimension such as body size is to show that female choice in relation to that dimension is effectively transitive. That is to say that rational, transitive female choice should not be assumed a priori, but assessed experimentally. Beyond the assessment of rationality in mate choice, analysis of transitivity may potentially help to identify the decision rules underlying mate choice and mating patterns.

In a sequence of binary choices, 40 females were confronted with dyads of males differing in size. We formed 20 triplets of males, consisting of one small male (S), one medium size male (M), and one large male (L). Each triplet of males was assigned to one pair of females consisting of one large and one small female (Figure 1). Each female was sequentially presented to one of the three possible male dyads (L vs. M, M vs. S, and L vs. S). For each female, we determined her preference ranking of the males according to pairwise comparisons over the three trials, based on a preference index above $50 \%$.

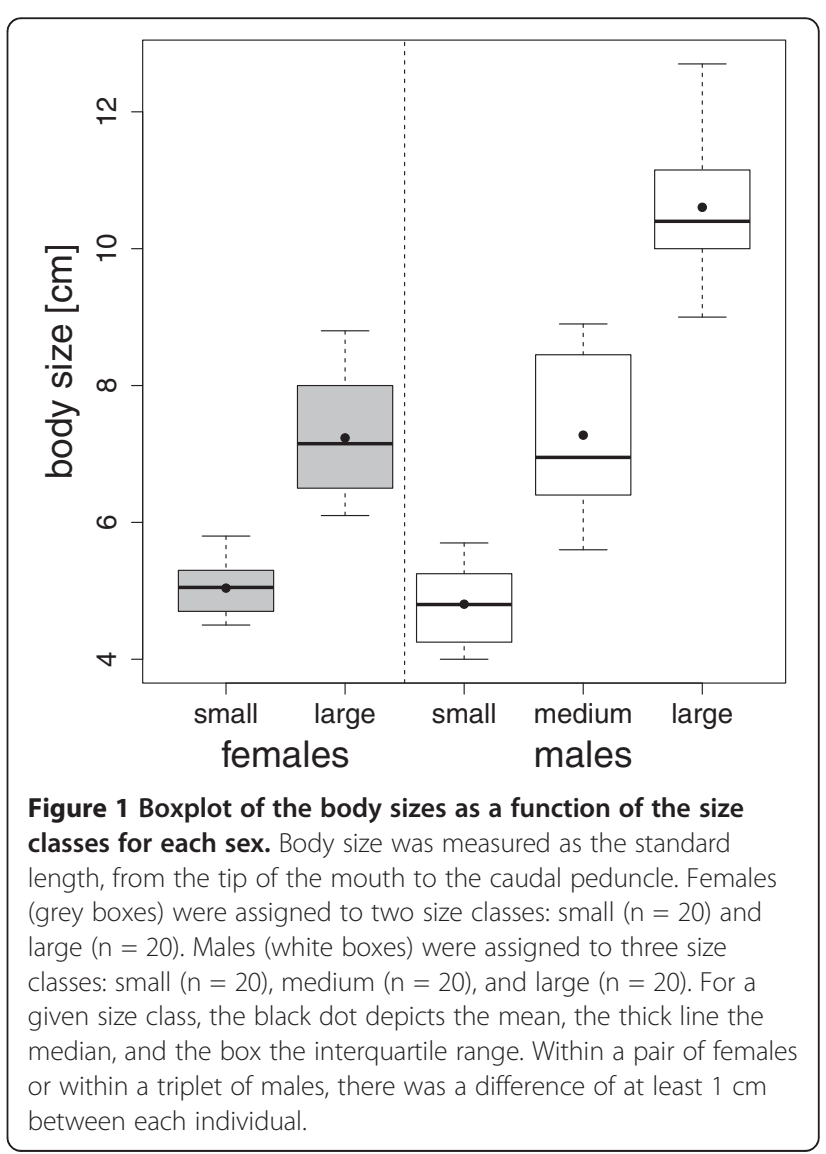


Table 1 Number of transitive or intransitive choices as a function of the size of the female

\begin{tabular}{|c|c|c|c|c|c|c|c|c|}
\hline \multirow[b]{2}{*}{ Female size } & \multicolumn{6}{|c|}{ Transitive order } & \multirow{2}{*}{$\begin{array}{c}\text { Intransitive order } \\
\qquad L>M>S>L\end{array}$} & \multirow[t]{2}{*}{ Tota } \\
\hline & $L>M>S$ & $L>S>M$ & $M>L>S$ & $M>S>L$ & $S>L>M$ & $S>M>L$ & & \\
\hline Small & 2 & 1 & 3 & 5 & 1 & 7 & 1 & 20 \\
\hline Large & 8 & 2 & 3 & 3 & 0 & 1 & 3 & 20 \\
\hline Total & 10 & 3 & 6 & 8 & 1 & 8 & 4 & 40 \\
\hline
\end{tabular}

Notation $L>M>S$ reflects transitive ordering in which a female preferred the larger male over the medium size male $(L>M)$, the medium size male over the smaller one $(M>S)$, and the larger male over the smaller one $(L>S)$. Four intransitive females exhibited the circular triad: $L>M, M>S$, and $S>L$.

Our results are qualitatively unchanged if we use a stricter criterion of preference index larger than 55\% (see Additional file 1). We show that both large and small female convict cichlids show significant SST when choosing between males of different size. In addition, we show that a simple self-referent directional rule, assuming that females prefer males which are about 30\% larger than themselves, performs particularly well at predicting observed transitive choices.

\section{Results}

\section{Transitivity}

Females exhibited marked preferences, as the mean proportion of time spent in front of the preferred male was $71.5 \%$ (bootstrapped $95 \% \mathrm{CI}=68 \%$ to $74 \%$ ). This mean preference index was not correlated between the large and small females from the same pair (Pearson correlation coefficient $\mathrm{r}=0.11$ with $95 \% \mathrm{CI}=-0.35$ to 0.53 , $\mathrm{n}=20, \mathrm{p}=0.64)$. The mean proportion of total time spent in the no-choice (neutral) area was $12 \%(95 \% \mathrm{CI}=10 \%$ to $14 \%$ ) and was not correlated between the large and small females from the same pair $(\mathrm{r}=0.16$ with $95 \% \mathrm{CI}=-0.30$ to $0.52, \mathrm{n}=20, \mathrm{p}=0.49$ ).

Based on preference index larger than $50 \%$, we observed transitive mate choice for 19 out of 20 large females and 17 out of 20 small ones (Table 1), with no difference between these two groups (Fisher exact test, $P=0.60$ ). Overall, transitivity was significantly more frequent than expected by chance (exact binomial test $\mathrm{B}(40,0.75), \mathrm{p}=0.016)$. Intransitivity could not be linked to a given triplet of males: intransitive females belonged to different pairs and, thus, they were presented to different triplets of males. Intransitivity could not be explained by a less decisive female behaviour either. There was no evidence that intransitive females made less pronounced choices than transitive ones, as both the preference index $(\mathrm{F}=0.83, \mathrm{df}=1$ and $38, \mathrm{p}=0.37)$ and the time spent in the neutral area $(\mathrm{F}=0.45, \mathrm{df}=1$ and 38 , $\mathrm{p}=0.51$ ) did not differ between the two groups.

An overall comparison revealed that the preference indexes of the 36 transitive females strongly differed between the three dyads of males (Figure 2, $\mathrm{F}=8.16, \mathrm{df}=2$ and $70, p=0.0007)$. Mean preference index was significantly higher when the females had to choose between males of distant ranks (male 1 vs. male 3, i.e. their most preferred and least preferred males), compared to when choosing between males of adjacent ranks (male 1 vs. male $2, \mathrm{p}=0.0028$; male 2 vs. male3, $\mathrm{p}=0.0003$ ), whereas the preference index when choosing between male 1 vs. male 2 did not differ from that when choosing between male 2 vs. male $3(\mathrm{p}=0.24)$. We observed a significant correlation between the preference for male 1 vs male 3 and the mean preference for male 1 vs male 2 and male 2 vs male 3 (Pearson correlation coefficient $r=0.39$, 95\% CI from 0.065 to $0.63, \mathrm{p}=0.020$; in Additional file 1 : Figure S1). The females which exhibited strong preference for male 1 vs male 2 or male 2 vs male 3 exhibited even stronger preference for male 1 vs male 3 , thus providing evidence for strong stochastic transitivity in female convict cichlids.

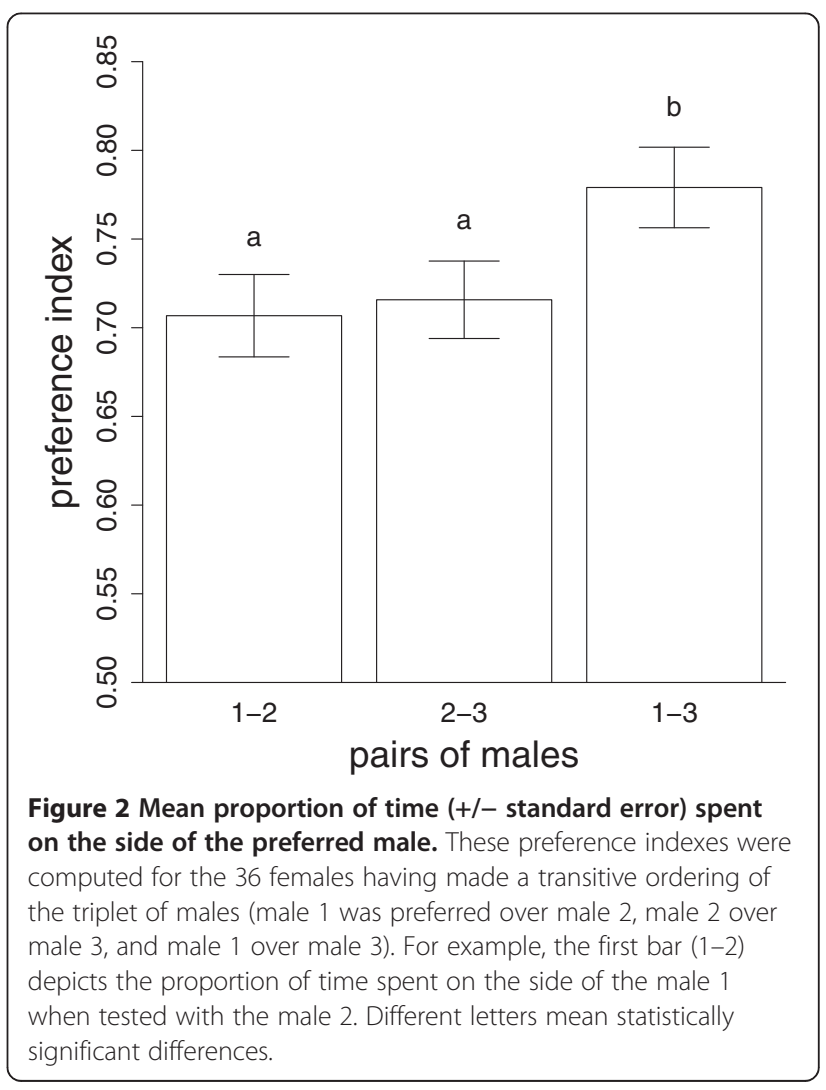




\section{Self-referent preference rule}

According to the Condorcet criterion, the most widely accepted normative standard for rational social choice [49], we defined that size class $M$ was socially preferred over choice alternative $S(M>S)$ when a majority of females preferred $M$ over $S$ than $S$ over $M$. Using such ranked pairs at the population level, our data support the social transitive ordering $\mathrm{M}>\mathrm{S}>\mathrm{L}$. This ordering is consistent with previous observations at group level: females presented with three males of different sizes chose most often the medium-sized male [44]. However, we argue for a cautious interpretation of such pairwise majority aggregation of individual preference. It may not reflect individual preferences [50]. Indeed, mean male size decreased with rank preference for small females (Figure 3A, $\mathrm{F}=4.11, \mathrm{df}=2$ and $36, \mathrm{p}=0.024)$, whereas it increased for large ones (Figure 3B, $\mathrm{F}=8.52, \mathrm{df}=2,32, \mathrm{p}=0.001$ ). There was no evidence for unconditional preference for either the largest male or the medium-sized one. On the contrary, the size of the most preferred male (male 1) increased with female size $(\mathrm{F}=19.35, \mathrm{df}=1$ and $34, \mathrm{p}=0.0001)$, potentially favouring a strong pattern of homogamy (Pearson's correlation coefficient $\mathrm{r}=0.6$ with $95 \% \mathrm{CI}=0.34$ to 0.77 ), consistent with that previously reported in natural populations, $\mathrm{r}=0.57$ [51].

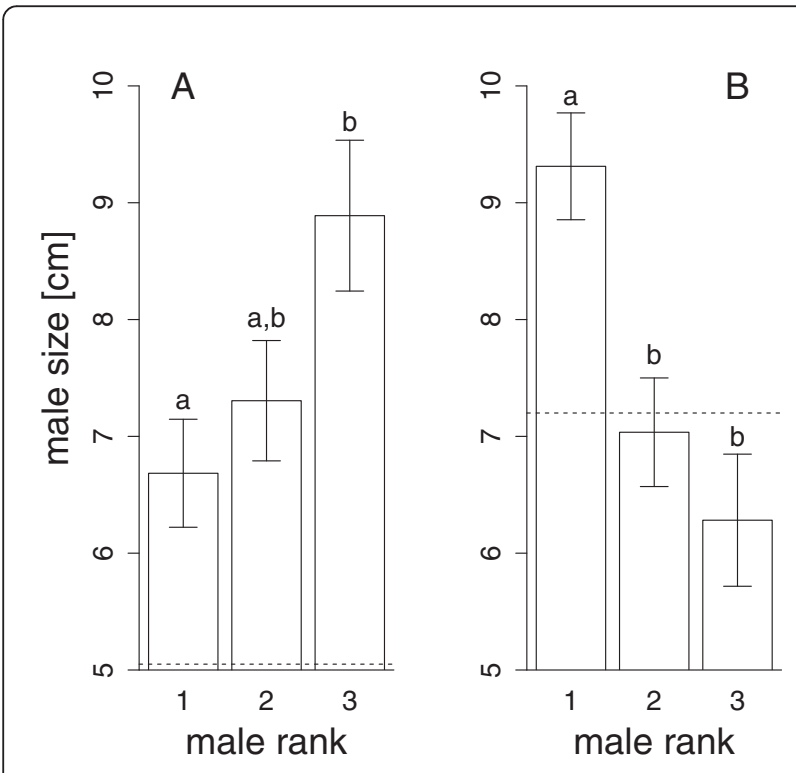

Figure 3 Mean male size (+/- standard error) as a function of their rank by the transitive females. The body size was measured as the standard length, from the tip of the mouth to the caudal peduncle. The mean male sizes were computed for the 36 females having made a transitive ordering of the triplet of males: male 1 was preferred over male 2, male 2 over male 3, and male 1 over male 3. Different letters mean statistically significant difference. The horizontal dotted line depicts the mean female size. (A) Choice made by the smaller females $(n=19)$. (B) Choice made by the larger females $(n=17)$.
We tested the hypothesis that females showed selfreferent directional preference for male size, in such a way that the preferred male size corresponded to a fixed ratio $\lambda$ to that of the female. Most accurate predictions for male 1 were achieved for $\lambda$ values ranging from 1.29 to 1.32 (Figure 4). With $\lambda=1.30$ (i.e. females prefer males $30 \%$ larger than themselves), male 1 was successfully indentified more often than expected by chance (Table 2). This ratio also gave the best prediction rates for linear order of the three males and for choice between two males in pairwise comparison. Each prediction was significantly more accurate than random choice (Table 2). In addition, rules assuming directional preference (for the largest male) or homotypic preference (for a male of similar size as the female) led to less accurate predictions, which were not statistically different from random choice (Table 2).

\section{Discussion}

The present study constitutes the first evidence for strong transitivity in a mate choice context. Evidence for SST suggests not only that female convict cichlids showed ordinal preference (as required under WST), but also that the direction and magnitude of their preferences between dyads of males could be predicted from their relative scaled values, as the difference between WST and SST is qualitatively similar to the difference between an ordinal and an interval scale [26]. Note however that the consistency of

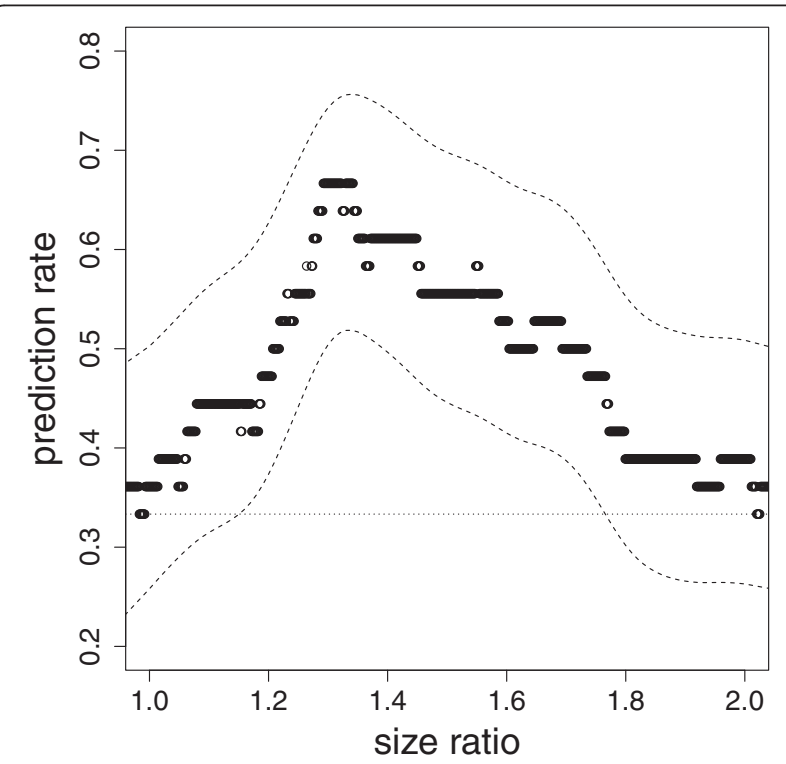

Figure 4 Proportion of correct predictions of the preferred male as a function of the ideal size ratio. For a given size ratio $(\lambda=$ ideal male size/female size), a female was assumed to prefer the male leading to the ratio that was the closest to this ideal one. The dashed curves show bootstrapped 95\% confidence interval around the prediction. The horizontal dotted line shows random choice (one in three chances of choosing the preferred male). 
Table 2 Prediction rate of the female choice as a function of the assumed preference rules

\begin{tabular}{llll}
\hline & \multicolumn{2}{l}{ Prediction rate } & \\
\cline { 2 - 4 } & Male 1 & Linear order & Pairwise comparison \\
\hline Random choice & $33 \%$ & $17 \%$ & $50 \%$ \\
$\begin{array}{l}\text { Directional } \\
\text { preference }\end{array}$ & $36 \%[19 \%-50 \%]$ & $28 \%[14 \%-42 \%]$ & $53 \%[41 \%-64 \%]$ \\
$\begin{array}{l}\text { Homotypic } \\
\text { preference }\end{array}$ & $36 \%[19 \%-50 \%]$ & $25 \%[11 \%-39 \%]$ & $61 \%[50 \%-70 \%]$ \\
$\begin{array}{l}\text { Self-referent } \\
\text { preference }\end{array}$ & $67 \%[52 \%-76 \%]$ & $42 \%[25 \%-58 \%]$ & $78 \%[72 \%-84 \%]$ \\
\hline
\end{tabular}

Accurate prediction rate (with bootstrapped $95 \% \mathrm{Cl}$ in square brackets) of the most preferred male (male 1), linear order of the three males (male $1>$ male $2>$ male 3 ), and choice between two males in pairwise comparison as a function of the assumed preference rules: directional preference for the largest male, homotypic preference for a male of similar size to the female, or self-referent directional preference for males 30\% larger than the female (Male/Female size ratio $\lambda=1.3$ ).

preference over time of transitive and intransitive females was not examined in the present study. It would therefore be valuable to assess in the future to what extent transitivity in mate choice is a characteristic of populations, or varies between individuals, possibly in relation to variation in age or personality, as the latter has recently been found to affect the measurement of female mate choice in vertebrates [52].

Due to the scarcity of empirical studies, it is difficult to contrast this first result with those of other studies. Kirkpatrick et al. [12] found no evidence for transitive or intransitive mate choice in females Tungara frogs, Physalaemus pustulosus. On the other hand, strong transitivity in a non-sexual context has been reported in some species, e.g. the unicellular slime mould Physarum polycephalum [53], European starlings Sturnus vulgaris [19,20], and domestic hens Gallus gallus domesticus [26], whereas both honey bees, Apis mellifera [17], and gray jays Perisoreus canadensis [18] were found to make intransitive foraging choices. Multidimensional choice [54] is often expected to lead to intransitive choice [1-3], unless animals are able to combine several criteria in a single common currency for fitness [46,55-57]. Our results thus suggest that male size could be an integrative criterion by which female convict cichlids assess the quality of potential mates. Indeed, body size of male convict cichlids has been found to correlate with several other traits such as aggressiveness [58], fighting ability [59], level of parental care [35], or nest site quality [60]. Although other male phenotypic attributes might be indicative of their quality, they may not necessarily be correlated with each other, and, hence, could be extremely complex to process simultaneously $[61,62]$. When faced with limited time and computational ability, animals are expected to rely on rules of thumb [63-65] such as fast and frugal heuristics that economize on computation by focusing on a limited number of cues [66]. Indeed, body size has been found to be the main male trait influencing female choice in several fish species [67,68]. Although it might be difficult to assess small size differences precisely $[69,70]$, male body size should be quicker and easier to assess reliably than, for instance, level of paternal care or compatibility between mates [71,72].

Furthermore, our results strongly suggest that female convict cichlids do not use male body size as an absolute criterion, but, instead, as a relative one. Overall, females showed a consistent directional preference for males larger than themselves, but did not systematically prefer the largest male in a triplet. Instead, individual preference function reached a maximum for males approximately one third larger than the female $(\lambda=1.3)$. This is particularly interesting as much of the published evidence for female choice based on male size in convict cichlids remains inconclusive. For instance, using similar designs, some studies reported a preference for the larger of two males [30,42] whereas some others found no such an effect [73]. These results may not be as inconsistent as they appear if one considers that a female's preference for male size is proportional to her own size. Several studies on convict cichlids have shown that females benefit from mating with a larger male, in terms of breeding success [34] and protection of offspring against predators [35]. However, male preference for larger, more fecund females $[39,74]$ and female-female competition may contribute to shape female preference for male size [33]. In the case of costly competition for mates, the poorest competitors may benefit from avoiding high-quality partners or targeting low-quality ones, in order to minimize costs [75-77]. This might be particularly relevant for convict cichlids, where a female's attractiveness to males has been found to be a function of her size relative to that of other females [74]. When mate choice is mutual, a female may thus save time and energy through directly attempting to mate with an individual of rank (in quality) similar to herself. In that respect, it is important to note that a self-referent directional preference (SRDP) for size is equivalent to a homotypic preference for rank in quality, if ranking in quality according to size does not differ between sexes (which is the case in cichlid fish where social dominance is linearly related to body size in both males and females [41]), and if the coefficient of SRDP precisely matches the degree of sexual dimorphism on the trait. Interestingly, the $\lambda$ value leading to the most accurate predictions of choice in the present study, ranging from 1.29 to 1.32 , is closely related to the level of sexual dimorphism observed in natural populations, where mean male length is about 30\% larger than mean female length [30]. The $\lambda$ value is also consistent with the size ratio (ranging from 1.27 to 1.35 ) observed within paired males and females $[44,51,60]$. In addition, any rule of thumb used in mating decisions should be flexible enough to accommodate changes in the social status of the animal through time, 
particularly when social status is directly related to size, and maximum size is not reached at sexual maturity. A SRDP for size might then be particularly relevant in species with mutual mate choice and continuous growth, such as monogamous fish, when individual quality is closely related to body size in both sexes.

A SRDP based on female size was, however, able to explain only four $(\mathrm{L}>\mathrm{M}>\mathrm{S}, \mathrm{M}>\mathrm{L}>\mathrm{S}, \mathrm{M}>\mathrm{S}>\mathrm{L}$ and $\mathrm{S}>\mathrm{M}>\mathrm{L}$ ) out of the six transitive orderings that were observed in the present study. Four females showed transitive ordering that are not consistent with a SRDP: $\mathrm{L}>\mathrm{S}>$ $\mathrm{M}$ and $\mathrm{S}>\mathrm{L}>\mathrm{M}$. One possibility is that females might be subject to errors in their decision making [47,78-80]. It is also possible that a few females did not rely only on male body size relative to their own, but considered additional cues to make a choice $[54,55]$. If these cues vary independently or are only weakly correlated with size, they might explain the observed deviations from the four orderings predicted by the SRDP based on size only, including intransitive orderings $[47,62,81]$.

Experimental evidence for transitivity in female convict cichlid preference may suggest that mating patterns observed in the wild result from rational mate choice. Mate preference, however, must be kept distinct from mate choice [82-84], as the preference relates to the sensory and behavioural components underlying female's willingness to mate with given male phenotypes, whereas mate choice results from the interaction between preference and external elements such as male availability, intrasexual competition $[33,68,85]$, and the cost of choosing [57]. On the other hand, our finding might be important to understand the dynamics of size-assortative mating in natural populations. Size-assortative mating is a pervasive pattern of mating in natural populations [86], particularly in monogamous fish species [87-89], including convict cichlids [74,90-92]. Although size-assortative mating can be produced independently of active mate choice, either through heterogeneity in spatial [93] or temporal [94] distribution of potential mates or through intrasexual competition [85], active mate choice may contribute to generate the observed patterns of size assortment between mates $[88,95]$. Still, the exact nature of the preference underlying observed patterns of size-assortative mating often remains unidentified $[94,96]$. In particular, patterns of phenotypic assortment can correspond to either a homotypic preference (or preference for one's own type, [86,97,98]) or a directional one ([86]; or type preference [97,99]), or a combination of both at the population level. In practice, however, it is difficult to infer the individual process of mating from the mere consideration of mating patterns at population level $[85,94,97,100]$. Our results suggest that examining transitivity in mate choice in both males and females may help to understand how assortative mating occurs in natural populations.

\section{Conclusion}

In summary, we performed an experimental study investigating the transitivity of choice, one key component of rationality, in a sexual context. Several authors have proposed that choice between partners might be intransitive $[1,2,12]$. This study provides the first evidence for strong stochastic transitivity in a context of mate choice. The females exhibited an ordinal preference, and the direction and magnitudes of this preference could be predicted from a simple comparative rule. We argue that the females did not necessarily compare two males to choose the best one. It is sufficient to assume that they used a self-referent evaluation based on their own size: females preferred male about one third larger than themselves. Such a decision rule has important implications for the evolution of the mate sampling strategies as it is less cognitively demanding than the comparative evaluation of the value of several males encountered sequentially. Several species have been reported to be able of self body-size perception [101]. In addition, they can constantly update the estimation of their physical characteristics, which is of crucial importance in case of continuous growth. Perception of spatial layout could be achieved when interacting with the environment, for instance, when the individual pass through various size apertures [102,103]. Social experience and direct interaction with conspecifics may also be involved in the constant reassessment of their physical ability or ressource holding potentiel [104-106]. Females Convict cichlid can use their body length as a template, and, importantly, may not have to learn and adjust their decision criterion across their lifetime as their template would systematically increase with their size. Finally, this decision criterion is consistent with patterns of assortative mating repeatedly observed at the population level.

\section{Materials and methods \\ Biological material}

One hundred convict cichlids (40 females, 60 males) were purchased from local commercial distributors. In the laboratory, they were maintained in 90 to $250 \mathrm{~L}$ tanks filled with water which was aerated and chemically and biologically filtered, at $25 \pm 1^{\circ} \mathrm{C}$ under a 12:12-h light:dark cycle. Fish were fed twice a day to satiation with Tetramin cichlid flakes. The sexes were kept separately for two months before the experiments started in order to control for previous breeding experience and ensure sexual receptivity. Prior to the experiments, we formed 20 pairs of females, consisting of one small and one large female with a difference of at least $1 \mathrm{~cm}$ between them (Figure 1), and 20 triplets of males, consisting of one small male (S), one medium size male $(\mathrm{M})$ and one large male (L) with a difference of at least $1 \mathrm{~cm}$ between each individual (Figure 1). We then randomly assigned each triplet of males to one of the female pairs. This paired design was adopted to ensure 
that potential differences in behavior between females of different sizes would not be due to any differences between the males they faced. All individuals were sexually mature at the time of the experiment.

\section{Experimental procedure}

In order to assess transitivity in choice, each female was tested on three separate occasions in a two-way choice apparatus consisting of a $90 \mathrm{~L}$ aquarium partitioned into three sections with two leakproof glass partitions [30,42]. The left and right end sections each contained one male, while the central compartment contained the female. The central compartment was delineated into three areas (the left choice area in front of the left male, the central, or neutral, area, and the right choice area in front of the right male), using two opaque plastic partitions. These partitions were placed in the female's compartment in such a way that the female could freely swim from one side of the compartment to the other without being able to see both males at the same time [30]. These partitions removed any effect of male-male competition through preventing visual interactions between them. The aquarium was lit by one daylight neon lamp tube (Sylvania Aquastar $30 \mathrm{~W}$, $10000{ }^{\circ} \mathrm{K}$ ) situated $10 \mathrm{~cm}$ above water level, while the room was maintained in the dark.

All individuals experienced only one test per day in order to limit contrast effects between trials (thus satisfying the assumption of independent and identically distributed random variables, [16]). Before each test, a 22 h-period of acclimatization took place, during which females were separated from males by opaque dividers. Positions of the males in the choice apparatus were randomized to avoid any bias associated with a systematic female preference for one side of the aquarium. In addition, the order of presentation of the different male dyads ( $\mathrm{L} v s$. M, M vs. S, and L vs. S) was randomized across tests to avoid primacy or recency effects [84,107]. Each test then lasted for two hours, during which time the female's position was continuously recorded with a digital video camera (JVC Everio GZMG21) positioned in front of the aquarium. The study was carried out in accordance with the ethical standards of the the French National Centre for Scientific Research and was approved by the government authorities (permit n²1-CC-EL-21).

\section{Transitivity}

We assessed both WST and SST from the preference expressed by females in the choice apparatus. A female was assumed to prefer male A over male B when the preference index (amount of time spent in front of male A divided by the total amount of time spent in the two choice areas) was above $50 \%$. With three alternatives $(\mathrm{L}, \mathrm{M}, \mathrm{S})$, there are six possible transitive triads $(\mathrm{L}>\mathrm{M}>\mathrm{S}$, $\mathrm{L}>\mathrm{S}>\mathrm{M}, \mathrm{M}>\mathrm{L}>\mathrm{S}, \mathrm{M}>\mathrm{S}>\mathrm{L}, \mathrm{S}>\mathrm{L}>\mathrm{M}$, and
$\mathrm{S}>\mathrm{M}>\mathrm{L}$ ), while non-transitive orderings can only occur with either $\mathrm{L}>\mathrm{M}>\mathrm{S}>\mathrm{L}$ or $\mathrm{S}>\mathrm{M}>\mathrm{L}>\mathrm{S}$ circular triads [108]. We assessed the degree of weak stochastic intransitivity as the proportion of circular triads [14]. We considered that the females made transitive choices if transitive ordering occurred more often than expected by chance (Binomial test with expected proportion of 6 transitive choices out of 8 ). For each female having made transitive choices (WST), we could then order the three males by order of decreasing female preference, from the most preferred male (male 1) to the least preferred one (male $3)$. Under the assumption of SST, the preference for male 1 when opposed to male 3 was expected to be higher than both the preference for male 1 when opposed to male 2 and that for male 2 when opposed to male 3 .

\section{Mate choice rule}

In order to assess which rule was used by females, we considered several candidate rules - namely a directional preference for the largest male, a homotypic preference for a male of similar size to the female, or a self-referent directional preference - and compared their ability to predict the female's choice. In the later rule, the preferred male size was assumed to correspond to a fixed ratio to that of the female. For a given female of size $S$, we assumed that her ideal male size would be equal to $\lambda \times S$, where $\lambda$ denotes the value of the ideal ratio [68]. We then ranked the three males presented to the female according to their absolute difference with the predicted ideal male size, with the predicted preferred male being the individual whose size would be the closest to $(\lambda \times S)$, and so on. For each rule, we calculated the proportion of accurate predictions for the most preferred male (male 1), the linear order of the three males (male $1>$ male $2>$ male 3 ), or the preferred male in each pairwise comparison. Non-parametric bootstrap estimates were computed to assess the statistical confidence of predicted choice outcomes and compare prediction rate between rules [50].

\section{Statistical analysis}

Data were inspected for homoscedasticity using the Brown-Forsythe test, and for normality using ShapiroWilk test, prior to the use of parametric tests. Proportions were normalized using square root-arcsine transformation. Differences in preference index between trials, and differences in male size as a function of their rank were analyzed using mixed-effect models including random slope to take into account repeated measures from the same females [109], using nlme package in R. Tukey's post-hoc comparisons were performed using glht package. The Pearson correlation coefficient between female size and that of her most preferred male (male 1) was used as a measure of assortative mating [110]. All the tests were performed using R 3.0 software [111]. 


\section{Additional file}

\section{Additional file 1: Supplementary materials.}

\section{Competing financial interests}

The authors declare that they have no competing interests.

\section{Authors' contributions}

F-XDM, MF and FC designed research, F-XDM, MF, SM performed research, F-XDM and FC analysed the data, F-XDM and FC wrote the paper. All authors read and approved the final manuscript.

\section{Acknowledgements}

We thank Luc-Alain Giraldeau and two anonymous referees for helpful comment about the MS. We also thank Pierick Mouginot, Elise Dirand, and Aurore Pernat for help in the experiments. Financial support was partly provided by a BQR research grant from the University of Burgundy and a HCPER grant from the Burgundy Regional Council.

\section{Author details}

${ }^{1}$ Équipe écologie évolutive, UMR CNRS 6282 Biogéosciences, Université de Bourgogne, 6 boulevard Gabriel, 21000 Dijon, France. ${ }^{2}$ Institut Universitaire de France, France.

\section{Received: 11 April 2013 Accepted: 1 November 2013}

Published: 11 November 2013

\section{References}

1. Bateson M, Healy SD: Comparative evaluation and its implications for mate choice. Trends Ecol Evol 2005, 20:659-664.

2. Ryan MJ, Akre KL, Kirkpatrick M: Mate choice. Curr Biol 2007, 17:R313-R316.

3. Houston Al, McNamara JM, Steer MD: Do we expect natural selection to produce rational behaviour? Philos Trans R Soc B Biol Sci 2007, 362:1531-1543.

4. Ryan MJ, Akre KL, Kirkpatrick M: Cognitive mate choice. In Cognitive Ecology II. Edited by Dukas R, Ratcliffe JM. Chicago: University Of Chicago Press; 2009:137-155.

5. Andersson M: Sexual Selection. Princeton, New Jersey: Princeton University Press; 1994.

6. Iwasa Y, Pomiankowski A: The evolution of mate preferences for multiple sexual ornaments. Evolution 1994, 48:853-867.

7. Kirkpatrick M: Good genes and direct selection in the evolution of mating preferences. Evolution 1996, 50:2125-2140.

8. Kacelnik A: Meanings of rationality. In Rational Animal. Edited by Hurley S, Nudds M. Oxford: Oxford University Press; 2006:87-105.

9. Bell AM, Hankison SJ, Laskowski KL: The repeatability of behaviour: a meta-analysis. Anim Behav 2009, 77:771-783.

10. Royle NJ, Lindström J, Metcalfe NB: Context-dependent mate choice in relation to social composition in green swordtails Xiphophorus helleri. Behav Ecol 2008, 19:998-1005.

11. Reaney LT: Female preference for male phenotypic traits in a fiddler crab: do females use absolute or comparative evaluation? Anim Behav 2009, 77:139-143.

12. Kirkpatrick M, Rand A, Ryan MJ: Mate choice rules in animals. Anim Behav 2006, 71:1215-1225

13. West $L J$, Hankin RKS: Exact tests for two-way contingency tables with structural zeros. J Stat Softw 2008, 28:1-19.

14. Regenwetter M, Dana J, Davis-Stober CP: Testing transitivity of preferences on two-alternative forced choice data. Front Psychol 2010, 1:148.

15. Bar-Hillel M, Margalit A: How vicious are cycles of intransitive choice? Theory Decis 1988, 24:119-145.

16. Regenwetter M, Dana J, Davis-Stober CP: Transitivity of preferences. Psychol Rev 2011, 118:42-56.

17. Shafir S: Intransitivity of preferences in honey bees: support for "comparative" evaluation of foraging options. Anim Behav 1994, 48:55-67.

18. Waite TA: Intransitive preferences in hoarding gray jays (Perisoreus canadensis). Behav Ecol Sociobiol 2001, 50:116-121.

19. Schuck-Paim C, Kacelnik A: Rationality in risk-sensitive foraging choices by starlings. Anim Behav 2002, 64:869-879.
20. Aw JM, Vasconcelos M, Kacelnik A: How costs affect preferences: experiments on state dependence, hedonic state and within-trial contrast in starlings. Anim Behav 2011, 81:1117-1128.

21. Franks NR, Mallon EB, Bray HE, Hamilton MJ, Mischler TC: Strategies for choosing between alternatives with different attributes: exemplified by house-hunting ants. Anim Behav 2003, 65:215-223.

22. Pratt S: Behavioral mechanisms of collective nest-site choice by the ant Temnothorax curvispinosus. Insectes Soc 2005, 52:383-392.

23. De Vries $\mathrm{H}$ : Finding a dominance order most consistent with a linear hierarchy: a new procedure and review. Anim Behav 1998, 55:827-843.

24. Grosenick L, Clement TS, Fernald RD: Fish can infer social rank by observation alone. Nature 2007, 445:429-432

25. Navarick DJ, Fantino E: Transitivity as a property of choice. J Exp Anal Behav 1972, 18:389-401.

26. Sumpter $\mathrm{C}$, Temple W, Foster $\mathrm{T}$ : The transitivity of choices between different response requirements. J Exp Anal Behav 1999, 72:235-249.

27. Tversky A, Russo EJ: Substitutability and similarity in binary choices. J Math Psychol 1969, 6:1-12.

28. Grace RC: Violations of transitivity: Implications for a theory of contextual choice. J Exp Anal Behav 1993, 60:185-201

29. Houston Al: Natural selection and context-dependent values. Proc $R$ Soc London Ser B Biol Sci 1997, 264:1539-1541.

30. Noonan K: Female mate choice in the cichlid fish Cichlasoma nigrofasciatum. Anim Behav 1983, 31:1005-1010.

31. Leese JM: Sex differences in the function of pair bonding in the monogamous convict cichlid. Anim Behav 2012, 83:1187-1193.

32. Cleveland-Roberts A, Itzkowitz $M$ : The role of sex ratios and resource availability on the pre-mating behavior of a monogamous fish Behav Processes 2009, 80:46-50.

33. Lehtonen TK, Lindström K: Density-dependent sexual selection in the monogamous fish Archocentrus nigrofasciatus. Oikos 2008, 117:867-874.

34. Wisenden BD: Factors affecting reproductive success in free-ranging convict cichlids (Cichlasoma nigrofasciatum). Can J Zool 1994, 72:2177-2185.

35. Gagliardi-Seeley JL, Itzkowitz M: Male size predicts the ability to defend offspring in the biparental convict cichlid Archocentrus nigrofasciatus. J Fish Biol 2006, 69:1239-1244.

36. Turner GF: Partner attack inhibition in the convict cichlid, Cichlasoma (Archocentrus) nigrofasciatum. Behaviour 1987, 103:294-316.

37. Lavery RJ, Keenleyside MHA: Filial cannibalism in the biparental fish Cichlasoma nigrofasciatum (Pisces: Cichlidae) in response to early brood reductions. Ethology 1990, 86:326-338.

38. FitzGerald GJ: Filial cannibalism in fishes: Why do parents eat their offspring? Trends Ecol Evol 1992, 7:7-10

39. Nuttall DB, Keenleyside MHA: Mate choice by the male convict cichlid (Cichlasoma nigrofasciatum; Pisces, Cichlidae). Ethology 1993, 95:247-256

40. Triefenbach F, Itzkowitz M: Mate switching as a function of mate quality in convict cichlids, Cichlasoma nigrofasciatum. Anim Behav 1998 55:1263-1270

41. Gagliardi-Seeley J, Leese J, Santangelo N, Itzkowitz M: Mate choice in female convict cichlids (Amatitlania nigrofasciata) and the relationship between male size and dominance. J Ethol 2009, 27:249-254.

42. Dechaume-Moncharmont F-X, Cornuau JH, Keddar I, Ihle M, Motreuil S, Cézilly F: Rapid assessment of female preference for male size predicts subsequent choice of spawning partner in a socially monogamous cichlid fish. C R Biol 2011, 334:906-910.

43. Beeching SC, Wack CL, Ruffner GL: Female convict cichlids (Archocentrus nigrofasciatus) prefer to consort with same-sized males. Ethol Ecol Evol 2004, 16:209-216.

44. Keenleyside MHA, Rangeley RW, Kuppers BU: Female mate choice and male parental defense behaviour in the cichlid fish Cichlasoma nigrofasciatum. Can J Zool 1985, 63:2489-2493.

45. Couldridge VCK, Alexander GJ: Does the time spent near a male predict female mate choice in a Malawian cichlid? J Fish Biol 2001, 59:667-672.

46. Tversky A: Intransitivity of preferences. Psychol Rev 1969, 76:31-48.

47. Trimmer PC: Optimal behaviour can violate the principle of regularity. Proc R Soc B Biol Sci 2013, 280:20130858

48. Morgan KV, Hurly TA, Bateson M, Asher L, Healy SD: Context-dependent decisions among options varying in a single dimension. Behav Processes 2012, 89:115-120.

49. Regenwetter M: Perspectives on preference aggregation. Perspect Psychol Sci 2009, 4:403-407. 
50. Regenwetter M, Grofman B, Popova A, Messner W, Davis-Stober CP, Cavagnaro DR: Behavioural social choice: a status report. Philos Trans R Soc B Biol Sci 2009, 364:833-843.

51. Alonzo JJ, McKaye KR, van den Berghe E: Parental defense of young by the convict cichlid, Archocentrus nigrofasciatus in Lake Xiloá, Nicaragua. J Aquaric Aquat Sci 2001, 9:209-228.

52. David M, Cézilly F: Personality may confound common measures of mate-choice. PLoS One 2011, 6:e24778.

53. Latty $T$, Beekman M: Irrational decision-making in an amoeboid organism: transitivity and context-dependent preferences. Proc R Soc B Biol Sci 2011 , 278:307-312.

54. Candolin U: The use of multiple cues in mate choice. Biol Rev 2003 78:575-595.

55. Van Doorn GS, Weissing FJ: The evolution of female preferences for multiple indicators of quality. Am Nat 2004, 164:173-186.

56. Hamilton PS, Sullivan BK: Female mate attraction in ornate tree lizards, Urosaurus ornatus: a multivariate analysis. Anim Behav 2005, 69:219-224.

57. Jennions MD, Petrie M: Variation in mate choice and mating preferences: A review of causes and consequences. Biol Rev 1997, 72:283-327.

58. Budaev SV, Zworykin DD, Mochek AD: Individual differences in parental care and behaviour profile in the convict cichlid: a correlation study. Anim Behav 1999, 58:195-202.

59. Copeland DL, Levay B, Sivaraman B, Beebe-Fugloni C, Earley RL: Metabolic costs of fighting are driven by contest performance in male convict cichlid fish. Anim Behav 2011, 82:271-280.

60. Wisenden BD: Reproductive behaviour of free-ranging convict cichlids, Cichlasoma nigrofasciatum. Environ Biol Fishes 1995, 43:121-134.

61. Vlaev I, Chater N, Stewart N, Brown GDA: Does the brain calculate value? Trends Cogn Sci 2011, 15:546-554.

62. Hagen EH, Chater N, Gallistel CR, Houston A, Kacelnik A, Kalenscher T, Nettle D, Oppenheimer D, Stephens DW: Decision making: what can evolution do for us? In Evolution and the mechanisms of decision making. Edited by Hammerstein P, Stevens JR. Cambridge, Massachusetts: The MIT Press; 2012:97-126.

63. Hutchinson JMC, Gigerenzer G: Simple heuristics and rules of thumb: Where psychologists and behavioural biologists might meet. Behav Processes 2005, 69:97-124

64. McNamara JM, Houston Al: Integrating function and mechanism Trends Ecol Evol 2009, 24:670-675.

65. Fawcett TW, Hamblin S, Giraldeau L-A: Exposing the behavioral gambit: the evolution of learning and decision rules. Behav Ecol 2013, 24:2-11.

66. Brandstätter E, Gigerenzer G, Hertwig R: The priority heuristic: Making choices without trade-offs. Psychol Rev 2006, 113:409-432.

67. Lehtonen TK, Lindström K: Females decide whether size matters: plastic mate preferences tuned to the intensity of male-male competition. Behav Ecol 2009, 20:195-199.

68. Labonne J, Augery M, Parade M, Brinkert S, Prevost E, Héland M, Beall E: Female preference for male body size in brown trout, Salmo trutta: is big still fashionable? Anim Behav 2009, 77:129-137.

69. Enquist $M$, Leimar $O$, Ljungberg $T$, Mallner $Y$, Segerdahl $N$ : A test of the sequential assessment game: fighting in the cichlid fish Nannacara anomala. Anim Behav 1990, 40:1-14.

70. Neat FC, Huntingford FA, Beveridge MM: Fighting and assessment in male cichlid fish: the effects of asymmetries in gonadal state and body size. Anim Behav 1998, 55:883-891.

71. Heuschele J, Mannerla M, Gienapp P, Candolin U: Environment-dependent use of mate choice cues in sticklebacks. Behav Ecol 2009, 20:1223-1227.

72. Thünken T, Meuthen $D$, Bakker TCM, Baldauf SA: A sex-specific trade-off between mating preferences for genetic compatibility and body size in a cichlid fish with mutual mate choice. Proc R Soc B Biol Sci 2012, 279:2959-2964.

73. Santangelo N: Courtship in the monogamous convict cichlid; what are individuals saying to rejected and selected mates? Anim Behav 2005, 69:143-149.

74. Beeching SC, Hopp AB: Male mate preference and size-assortative pairing in the convict cichlid. J Fish Biol 1999, 55:1001-1008.

75. Fawcett TW, Johnstone RA: Mate choice in the face of costly competition. Behav Ecol 2003, 14:771-779.

76. Venner S, Bernstein C, Dray S, Bel-Venner M-C: Make love not war: when should less competitive males choose low-quality but defendable females? Am Nat 2010, 175:1-14.
77. Stulp G, Buunk AP, Kurzban R, Verhulst S: The height of choosiness: mutual mate choice for stature results in suboptimal pair formation for both sexes. Anim Behav 2013, 86:37-46.

78. Johnson DDP, Blumstein DT, Fowler JH, Haselton MG: The evolution of error: error management, cognitive constraints, and adaptive decisionmaking biases. Trends Ecol Evol 2013, 28:474-481.

79. Kareev Y: Advantages of cognitive limitations. In Evolution and the mechanisms of decision making. Edited by Hammerstein P, Stevens JR. Cambridge, Massachusetts: The MIT Press; 2012:169-182.

80. Marshall JAR, Trimmer PC, Houston Al, McNamara JM: On evolutionary explanations of cognitive biases. Trends Ecol Evol 2013.

81. Houston Al, McNamara JM, Steer MD: Violations of transitivity under fitness maximization. Biol Lett 2007, 3:365-367.

82. Widemo F, Sæther SA: Beauty is in the eye of the beholder: causes and consequences of variation in mating preferences. Trends Ecol Evol 1999, $14: 26-31$.

83. Cotton S, Small J, Pomiankowski A: Sexual selection and condition-dependent mate preferences. Curr Biol 2006, 16:R755-R765.

84. Wagner WE: Measuring female mating preferences. Anim Behav 1998, 55:1029-1042

85. Taborsky B, Guyer L, Taborsky M: Size-assortative mating in the absence of mate choice. Anim Behav 2009, 77:439-448.

86. Cézilly F: Assortative mating. In Encycl Anim Behav vol 3. Edited by Bekoff M. Westport, Connecticut, USA: Greenwood Press; 2004:876-881.

87. Jiang Y, Bolnick DI, Kirkpatrick M: Assortative mating in animals. Am Nat 2013, 181:E125-E138.

88. Baldauf SA, Kullmann H, Schroth S, Thünken T, Bakker TCM: You can't always get what you want: size assortative mating by mutual mate choice as a resolution of sexual conflict. BMC Evol Biol 2009, 9:129.

89. Verzijden MN, ten Cate C: Early learning influences species assortative mating preferences in Lake Victoria cichlid fish. Biol Lett 2007, 3:134-136.

90. Leese J, Wilson H, Ganim A, Itzkowitz M: Effects of reversed size-assortative mating on spawning success in the monogamous convict cichlid, Amatitlania nigrofasciata. Ethol Ecol Evol 2010, 22:95-100.

91. Wisenden $\mathrm{BD}$, Lanfranconi-Izawa $\mathrm{TL}$, Keenleyside MHA: Fin digging and leaf lifting by the convict cichlid, Cichlasoma nigrofasciatum: examples of parental food provisioning. Anim Behav 1995, 49:623-631.

92. McKaye KR: Mate choice and size assortative pairing by the cichlid fishes of Lake Jiloá, Nicaragua. J Fish Biol 1986, 29:135-150.

93. Bollache L, Gambade G, Cézilly F: The influence of micro-habitat segregation on size assortative pairing in Gammarus pulex (L.) (Crustacea, Amphipoda). Arch für Hydrobiol 2000, 147:547-558.

94. Galipaud M, Bollache L, Dechaume-Moncharmont F-X: Assortative mating by size without a size-based preference: the female-sooner norm as a mate-guarding criterion. Anim Behav 2013, 85:35-41.

95. Ros AFH, Zeilstra I, Oliveira RF: Mate choice in the Galilee St. Peters fish Sarotherodon galilaeus. Behaviour 2003, 140:1173-1188.

96. Rowe L, Arnqvist $\mathrm{G}$ : Analysis of the causal components of assortative mating in water striders. Behav Ecol Sociobiol 1996, 38:279-286.

97. Burley N: The meaning of assortative mating. Ethol Sociobiol 1983, 4:191-203.

98. Castro L, Toro MA: Assortative mating through a mechanism of sexual selection. J Theor Biol 2006, 243:386-392.

99. Alpern S, Reyniers D: Strategic mating with common preferences. J Theor Biol 2005, 237:337-354

100. Kuijper B, Pen I, Weissing FJ: A guide to sexual selection theory. Annu Rev Ecol Evol Syst 2012, 43:311.

101. Ben-Nun A, Guershon M, Ayali A: Self body-size perception in an insect. Naturwissenschaften 2013, 100:479-484.

102. Stefanucci JK, Geuss MN: Big people, little world: the body influences size perception. Perception 2009, 38:1782-1795.

103. Fath AJ, Fajen BR: Static and dynamic visual information about the size and passability of an aperture. Perception 2011, 40:887-904.

104. Le Roux A, Bergman TJ: Indirect rival assessment in a social primate, Theropithecus gelada. Anim Behav 2012, 83:249-255.

105. Reddon AR, Voisin MR, Menon N, Marsh-Rollo SE, Wong MYL, Balshine S: Rules of engagement for resource contests in a social fish. Anim Behav 2011, 82:93-99.

106. Arnott G, Elwood RW: Assessment of fighting ability in animal contests. Anim Behav 2009, 77:991-1004. 
107. Wright AA, Santiago HC, Sands SF, Kendrick DF, Cook RG: Memory processing of serial lists by pigeons, monkeys, and people. Science 1985, 229:287-289.

108. Alway GG: The distribution of the number of circular triads in paired comparisons. Biometrika 1962, 49:265-269.

109. Schielzeth H, Forstmeier W: Conclusions beyond support: overconfident estimates in mixed models. Behav Ecol 2009, 20:416-420

110. Bollache L, Cézilly F: Sexual selection on male body size and assortative pairing in Gammarus pulex (Crustacea: Amphipoda): field surveys and laboratory experiments. J Zool 2004, 264:135-141.

111. R Core Team: $R$ a Language and Environment for Statistical Computing. Vienna, Austria: R Foundation for Statistical Computing; 2013.

\section{doi:10.1186/1742-9994-10-69}

Cite this article as: Dechaume-Moncharmont et al:: Female mate choice in convict cichlids is transitive and consistent with a self-referent directional preference. Frontiers in Zoology 2013 10:69.

\section{Submit your next manuscript to BioMed Central and take full advantage of:}

- Convenient online submission

- Thorough peer review

- No space constraints or color figure charges

- Immediate publication on acceptance

- Inclusion in PubMed, CAS, Scopus and Google Scholar

- Research which is freely available for redistribution 